\title{
BMJ Open Epilepsy and mortality: a retrospective cohort analysis with a nested case- control study identifying causes and risk factors from primary care and linkage-derived data
}

To cite: Wojewodka G, Gulliford MC, Ashworth M, et al. Epilepsy and mortality: a retrospective cohort analysis with a nested case-control study identifying causes and risk factors from primary care and linkage-derived data. BMJ Open 2021;11:e052841. doi:10.1136/ bmjopen-2021-052841

- Prepublication history and additional supplemental material for this paper are available online. To view these files, please visit the journal online (http://dx.doi.org/10.1136/ bmjopen-2021-052841)

Received 27 April 2021 Accepted 06 0ctober 2021

Check for updates

(C) Author(s) (or their employer(s)) 2022. Re-use permitted under CC BY-NC. No commercial re-use. See rights and permissions. Published by BMJ.

For numbered affiliations see end of article.

Correspondence to Dr Gabriella Wojewodka; gabriella.wojewodka@kcl.ac.uk

\section{ABSTRACT}

Objectives People with epilepsy (PWE) have a higher mortality rate than the general population. Epilepsy-related deaths have increased despite all-cause mortality decreasing in the general population pre-COVID-19. We hypothesised that clinical and lifestyle factors may identify people more at risk. Design We used a retrospective cohort study to explore cause of death and a nested case-control study to identify risk factors.

Setting We explored factors associated with mortality using primary care population data from 1 April 2004 to 31 March 2014. Data were obtained from the Clinical Practice Research Datalink which compiles anonymised patient data from primary care in the UK. Cause of death data was supplemented from the Office of National Statistics when available.

Participants The analysis included 70431 PWE, with 11241 registered deaths.

Results The number of deaths within the database increased by $69 \%$ between the first and last year of the study. Epilepsy was considered as a contributing cause in approximately $45 \%$ of deaths of PWE under 35 . Factors associated with increased risk of death included attendance at emergency departments and/or emergency admissions (OR 3.48,95\% $\mathrm{Cl} 3.19$ to 3.80 ), antiepileptic drug (AED) polytherapy (2 AEDs: OR 1.60,95\% Cl 1.51 to 1.71 ; 3 AEDs: OR $2.06,95 \% \mathrm{Cl} 1.86$ to $2.29 ; 4+A E D s:$ OR $2.62,95 \% \mathrm{Cl} 2.23$ to 3.08 ), status epilepticus (OR $2.78,95 \% \mathrm{Cl} 1.64$ to 4.71 ), depression (OR 1.67,95\% Cl 1.57 to 1.76 ) and injuries (OR $1.54,95 \% \mathrm{Cl} 1.43$ to 1.67 ). No seizures in the prior year (OR $0.52,95 \% \mathrm{Cl} 0.41$ to 0.65).

Conclusion Our results add to existing evidence that deaths in epilepsy are increasing. Future studies could focus on identifying PWE at high risk and addressing them with clinical interventions or better self-management. Identifying specific risk factors for younger people should be a priority as epilepsy may be a factor in close to half of deaths of PWE under 35 years of age.

\section{INTRODUCTION}

Epilepsy is one of the most common neurological conditions with about 50 million

\section{STRENGTHS AND LIMITATIONS OF THIS STUDY}

$\Rightarrow$ The study examines the higher mortality rate in epilepsy by exploring risk factors that could be mitigated by interventions in clinical practice.

$\Rightarrow$ The study included data collected in primary care which is large and representative compared with hospital data.

$\Rightarrow$ The large sample size collected from participating UK practices contributes to the generalisability of the results.

$\Rightarrow$ The dataset used was from 2004 to 2014, as this covered a period where epilepsy was part of a national programme for outcome reporting.

people affected worldwide. ${ }^{1}$ With access to good treatment, it is estimated that $60 \%-70 \%$ of people with epilepsy (PWE) can become free of seizure. ${ }^{2}$ However, epilepsy is also an important cause of premature death. ${ }^{3}$ Mortality rates of PWE are higher than for the general population. ${ }^{4-9}$ A longitudinal cohort study from Sweden found that an epilepsy diagnosis was associated with a 14-fold increased risk of all-cause death. ${ }^{5}$ Some studies suggest that this has not changed over time. ${ }^{410}$ Other data suggest the number of deaths in PWE is increasing despite a decrease in all-cause mortality in the general population. ${ }^{8} 1112$ Public Health England reported that deaths with epilepsy as a contributing factor increased by $70 \%$ between 2001 and 2014, while all-cause deaths in the population decreased by $6 \%{ }^{11}$

Some causes of death in PWE are similar to the general population, such as circulatory and respiratory diseases, dementia, Alzheimer's and cancers. ${ }^{11} 1314$ Others are related to consequences of the condition itself such as injuries, burns and drowning during seizures. ${ }^{5915}$ Lifestyle and psychosocial factors 
contribute to increased risk of mortality and include alcohol or substance misuse, ${ }^{13} 16$ low adherence to medication, ${ }^{10}$ depression ${ }^{516}$ and socioeconomic status. ${ }^{11} 16$ Sudden unexpected death in epilepsy (SUDEP) is sometimes posited as a common cause of death for PWE. A recent review suggests SUDEP accounts for $12 \%$ of allcause deaths in epilepsy. ${ }^{10}$ However, factors that can be prevented or treated are under-researched and could lead to more impact on reducing mortality.

In 2011, our group published risk factors increasing mortality in PWE based on population data collected in primary care in the UK between 1993 and 2007. ${ }^{16}$ Here, we follow up on the analysis using data collected during an incentivised programme which rewarded enhanced monitoring and care for PWE in primary care over 10 years. We hypothesised that the epilepsy data collected under this programme would be of high quality allowing for a comprehensive analysis of causes and risk factors associated with mortality. We report the number of deaths recorded during this time, the causes of death for younger and older PWE, and risk factors associated with mortality among PWE.

\section{METHODS}

\section{Study design}

A retrospective cohort design was used to analyse mortality and causes of death in PWE. Risk factors affecting mortality were analysed using a nested case-control study.

\section{Setting}

Data was obtained from the Clinical Practice Research Datalink (CPRD). This database contains anonymised patient data obtained from electronic records from primary care clinics in the UK. The data are sent from participating clinics to a central server where data is cleaned, checked for quality and curated. A study from 2015 counted 11299221 patients registered in the CPRD from 674 general practitioner (GP) practices. ${ }^{17}$ Patients in the database were representative of the UK population when compared with the 2011 census. ${ }^{17}$ For our study period, mid-year counts for 2004 show 4584065 patients were active in the database (alive and currently registered in a GP practice) with $50.1 \%$ being female. In 2013, 4 493034 patients were active at mid-year and $50.4 \%$ were female.

Our study period was from 1 April 2004 to 31 March 2014 during which epilepsy management came under the Quality and Outcomes Framework (QOF), a programme implemented within the primary care setting. Revised QOF clinical indicators were implemented in April 2014 when most epilepsy indicators were discontinued. The aim of the programme was to incentivise improvement in the recording of clinical information on specific lifestyle items or long-term health conditions with the view that structured monitoring and reporting improved the quality of care. ${ }^{18}$

\section{Types of data}

The CPRD includes 'patient data' which include demographic information, 'clinical data' include information on clinical events such as diagnosis or symptoms, and 'additional clinical details' that include lifestyle factors. It also includes 'therapy data' which contain information on prescriptions, product codes, doses and treatment schedules. Clinical data are entered initially as alpha numeric Read codes by the GP into electronic medical records. These are converted into numeric Medcodes within the CPRD for easier analysis by researchers. Medication types are recorded in 'therapy data' as numeric Prodcodes.

Cause of death information was obtained when available through linked data for a subset of patients from England and Wales from the Office of National Statistics (ONS). The cause of death is presented using International Classification of Diseases (ICD)-10 diagnostic codes and offers the main cause and up to 15 contributing causes, if applicable. Date of death was available both from the CPRD and ONS data and the earliest date of the two was used if there were discrepancies. The Index of Multiple Deprivation (IMD) was also obtained for each patient's GP practice, which was used for control matching in the case-control study. Practice IMD data were 'most up to date' version when requested in 2018.

\section{Cohort study participants}

For the mortality and cause of death cohort study, adults with epilepsy were included who were least 18 years old at time of death. Epilepsy was defined as having a documented epilepsy diagnostic code or seizure code and at least two prescriptions of antiepileptic drugs (AEDs). Using a diagnostic or seizure code with prescription data has been validated to identify cases of epilepsy in routinely collected data. ${ }^{19}$ Any patient with a diagnostic code of 'epilepsy resolved' was removed from the study (Medcodes 8385 and 12848, Read codes 2126000 and 212J.00). Codes used to identify epilepsy and seizures are presented in online supplemental table S1.

\section{Case-control study participants}

Since we were focusing on the specific 12-month period prior to date of death to establish preventable risk factors, we opted to use a nested case-control study design. Cases were defined as PWE within the cohort with a documented date of death between 1 April 2004 and 31 March 2014 with at least 12 months of data recorded in our study period (thus earliest data of death included was 1 April $2005)$. Controls were randomly matched at a ratio of $3: 1$ by sex, practice IMD, year of birth $( \pm 1$ year). For cases aged 18, controls were matched for year of birth +1 year. Controls were alive for at least 12 months after the date of death of their matched case. The first analysis was conducted for the whole dataset and a second one used data from PWE under the age of 35 . 


\section{Exposure variables}

Potential variables were selected based on existing literature, items part of the QOF and others associated with lifestyle. Exposure data were refined based on the availability and reliability of data in the CPRD. Full description of variables and sources of data are included in online supplemental file 1 . List of codes used for each variable can be found in online supplemental file 2 . We assessed variables occurring in the 12 months prior to the case's date of death for emergency department visits or emergency admissions, number of AEDs, status epilepticus, depression, injury, smoking status and seizure freedom. History of comorbidity was taken from all available patient data for dementia and stroke. Missing data was considered as 'no' for binary outcomes except for smoking status where the last known status was used, as previously reported. ${ }^{20}$ Variables that were considered but not included due to poor quality of data included alcohol and substance use.

\section{Statistics}

The number all-cause deaths recorded in the CPRD was calculated for complete calendar years (from 2005 to 2013) to allow for comparisons with previous publications. All other analyses used data from the full study period (1 April 2004 to 31 March 2014). The cause of death data was analysed two ways: (1) tabulating the main cause of death in PWE and (2) evaluating the proportion of deaths with epilepsy listed as a contributing cause. A contributing cause was defined as either the main cause or listed as a cause in any of the other 15 positions on the death certificate. The main causes of death are presented for younger and older PWE with 65 years as the cut-off. Deaths with epilepsy as a contributing cause were divided by age group. To track trends, an additional analysis of main cause of death by full calendar year is presented in supplemental material (online supplemental table S2).

Conditional logistic regression was used for the nested case-control study. Variables were included in the model following maximum likelihood and Akaike information criterion testing. Potential confounders such as age, sex and deprivation were addressed by control matching. Data are presented as ORs and 95\% CIs. The analysis was conducted for the whole dataset and subsequently for the subset of PWE aged under 35.

The following interactions were tested: age and emergency visit/admission, age and injury, age and dementia, age and stroke, status epilepticus and emergency visit/ admissions, number of AEDs and seizure freedom, prescription issue and number of AEDs, injury and emergency visit/admission.

\section{Patient and public involvement}

Patients or the public were not involved in the design, or conduct, or reporting, or dissemination plans of our research.
124,897 extracted from CPRD

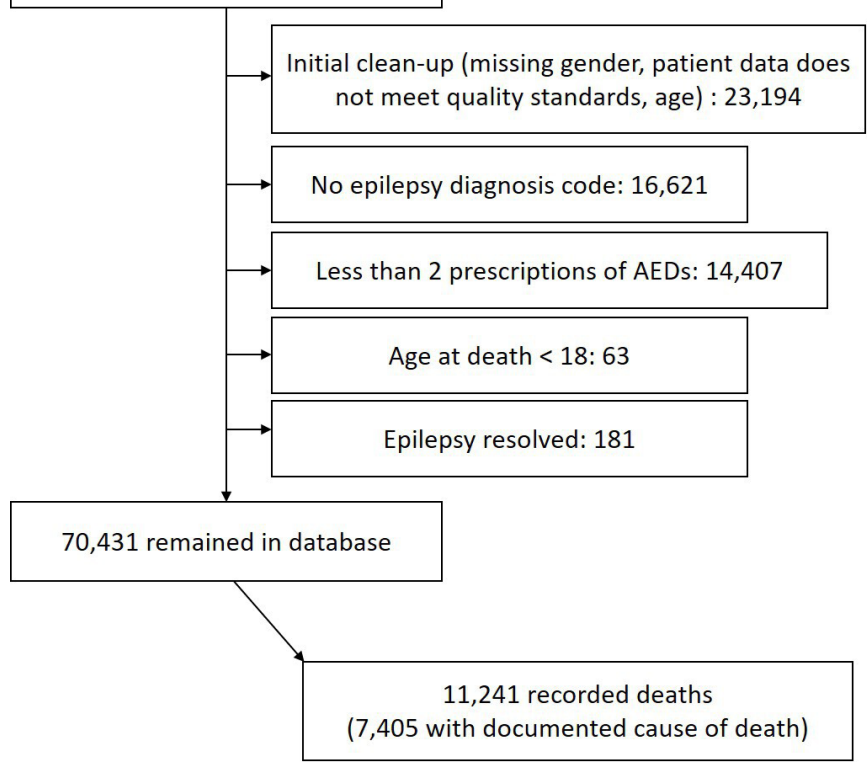

Figure 1 Flow chart of participant selection. AEDs, antiepileptic drugs; CPRD, Clinical Practice Research Datalink.

\section{RESULTS}

We obtained a sample size of 70431 PWE with 11241 who had a documented date of death within our time frame (figure 1). We obtained cause of death for 7405 people from ONS linked data. Age of patients ranged 18-105 with $50.8 \%$ male.

\section{Number of deaths}

The number of deaths recorded in the database increased between 2005 and 2013, from 821 to 1386 which represents a $68.8 \%$ increase (table 1 ). This increase was not attributed to more PWE being registered in the database as this decreased by $21.8 \%$ over the same period. The mean age of the participants within the database increased over time.

\section{Cause of death}

The main causes of death for PWE aged 18-64 years old were neoplasms $(26.9 \%)$, diseases of the circulatory system (15.6\%) and epilepsy (14.2\%) (table 2A). For PWE 65 years and over, the main causes of death were diseases of the circulatory system (37.3\%), neoplasms $(17.2 \%)$ and diseases of the respiratory system $(15.6 \%)$ (table 2B). Deaths due to epilepsy as a primary cause were documented in $2.7 \%$ of older PWE.

We tabulated the number of deaths with epilepsy listed as a cause of death, either the main or a contributing cause (table 3). In PWE under 35, almost $45 \%$ of deaths had epilepsy as a contributary cause $(35.1 \%-$ $53.3 \%$, with a mean of $44.2 \%$ ) (table 3 ). The trends are similar between sexes under 35 and over 65 . However, they differ in the middle age. At the 40-44 age group, epilepsy-contributing deaths were twofold higher in male compared with female PWE. 
Table 2 Documented main cause of death of people with epilepsy (A) under 65 years (B) aged 65 and over

\begin{tabular}{|c|c|}
\hline (A) ICD-10 category & $\begin{array}{l}\text { Under 65, } \\
\mathrm{n}(\%)\end{array}$ \\
\hline Neoplasms (C00-D48) & $571(26.9)$ \\
\hline Diseases of the circulatory system (100-199) & $330(15.6)$ \\
\hline Epilepsy (G40-G41) & $302(14.2)$ \\
\hline Diseases of the respiratory system (J00-J99) & $176(8.3)$ \\
\hline $\begin{array}{l}\text { Diseases of the nervous system (G00-G37, G43- } \\
\text { G99), excluding epilepsy }\end{array}$ & $164(7.7)$ \\
\hline Diseases of the digestive system (K00-KK93) & $161(7.6)$ \\
\hline $\begin{array}{l}\text { External causes of morbidity and mortality (V01- } \\
\text { X59, X85-Y98) }\end{array}$ & $129(6.1)$ \\
\hline $\begin{array}{l}\text { Congenital malformations, deformations and } \\
\text { chromosomal abnormalities (Q00-Q99) }\end{array}$ & $70(3.3)$ \\
\hline Mental and behavioural disorders (F00-F99) & $61(2.9)$ \\
\hline $\begin{array}{l}\text { Endocrine, nutritional and metabolic diseases } \\
\text { (E00-E90) }\end{array}$ & $34(1.6)$ \\
\hline $\begin{array}{l}\text { Symptoms, signs and abnormal clinical and } \\
\text { laboratory findings, not elsewhere classified } \\
\text { (R00-R99) }\end{array}$ & $29(1.4)$ \\
\hline $\begin{array}{l}\text { External causes of morbidity and mortality } \\
\text { (intentional) (X60-X84) }\end{array}$ & $28(1.3)$ \\
\hline Diseases of the genitourinary system (NO0-N99) & $23(1.1)$ \\
\hline $\begin{array}{l}\text { Certain infectious and parasitic diseases (A00- } \\
\text { B99) }\end{array}$ & $20(0.9)$ \\
\hline $\begin{array}{l}\text { Diseases of the blood and blood-forming organs } \\
\text { (D50-D89) }\end{array}$ & $9(0.4)$ \\
\hline $\begin{array}{l}\text { Diseases of the musculoskeletal system and } \\
\text { connective tissue (M00-M99) }\end{array}$ & $9(0.4)$ \\
\hline $\begin{array}{l}\text { Diseases of the skin and subcutaneous tissue } \\
\text { (L00-L99) }\end{array}$ & $4(0.2)$ \\
\hline Total & $2120(100.0)$ \\
\hline (B) ICD-10 category & $\begin{array}{l}65 \text { and over, } \\
\text { n (\%) }\end{array}$ \\
\hline Diseases of the circulatory system (100-199) & $1973(37.3)$ \\
\hline Neoplasms (C00-D48) & $910(17.2)$ \\
\hline Diseases of the respiratory system (J00-J99) & $827(15.6)$ \\
\hline Mental and behavioural disorders (F00-F99) & $479(9.1)$ \\
\hline $\begin{array}{l}\text { Diseases of the nervous system (G00-G37, G43- } \\
\text { G99), excluding epilepsy }\end{array}$ & $295(5.6)$ \\
\hline Diseases of the digestive system (KO0-KK93) & 173 (3.3) \\
\hline Epilepsy (G40-G41) & $142(2.7)$ \\
\hline Diseases of the genitourinary system (N00-N99) & $130(2.5)$ \\
\hline $\begin{array}{l}\text { External causes of morbidity and mortality (V01- } \\
X 59, X 85-Y 98)\end{array}$ & $88(1.7)$ \\
\hline $\begin{array}{l}\text { Symptoms, signs and abnormal clinical and } \\
\text { laboratory findings, not elsewhere classified } \\
\text { (R00-R99) }\end{array}$ & $86(1.6)$ \\
\hline $\begin{array}{l}\text { Endocrine, nutritional and metabolic diseases } \\
\text { (E00-E90) }\end{array}$ & $67(1.3)$ \\
\hline $\begin{array}{l}\text { Certain infectious and parasitic diseases (A00- } \\
\text { B99) }\end{array}$ & $46(0.9)$ \\
\hline
\end{tabular}


Table 2 Continued

\begin{tabular}{lc}
\hline (B) ICD-10 category & $\begin{array}{l}65 \text { and over, } \\
\mathbf{n}(\%)\end{array}$ \\
\hline $\begin{array}{l}\text { Diseases of the musculoskeletal system and } \\
\text { connective tissue (M00-M99) }\end{array}$ & $29(0.5)$ \\
\hline $\begin{array}{l}\text { Congenital malformations, deformations and } \\
\text { chromosomal abnormalities (Q00-Q99) }\end{array}$ & $15(0.3)$ \\
\hline $\begin{array}{l}\text { Diseases of the skin and subcutaneous tissue } \\
\text { (L00-L99) }\end{array}$ & $13(0.2)$ \\
\hline $\begin{array}{l}\text { Diseases of the blood and blood-forming organs } \\
\text { (D50-D89) }\end{array}$ & $8(0.2)$ \\
\hline $\begin{array}{l}\text { External causes of morbidity and mortality } \\
\text { (intentional) (X60-X84) }\end{array}$ & $4(0.1)$ \\
\hline \begin{tabular}{l} 
Total \\
\hline ICD, International Classification of Diseases.
\end{tabular} & \\
\hline
\end{tabular}

To explore whether there were changes in the causes of death over time, we tabulated the main cause of death by year (online supplemental table S2). Diseases of the circulatory system were consistently listed as the highest main cause of death for each year. The proportion of deaths due to mental and behavioural disorders doubled from 2011 onwards (mean percentage for 2005-2010: $5.05 \%$, mean percentage for 2011-2013: 10.7\%). The proportion of deaths attributed to epilepsy as the primary cause remained relatively stable throughout $(6.3 \%$ for 2005 to $5.2 \%$ for 2013 ), although the number of deaths this represented increased (33 in 2005 to 51 to 2013).

\section{Risk factors}

Risk factors included in the model, frequencies and associated ORs are presented in table 4. Attendance at emergency departments in the previous 12 months was associated with the highest risk (OR 3.48,95\% CI 3.19 to 3.80). Compared with being prescribed one AED, prescription of two or more AEDs was associated with an elevated risk of death (2 AEDs: OR 1.60, 95\% CI 1.51 to 1.71; 3 AEDs: OR 2.06, $95 \%$ CI 1.86 to 2.29 ; 4+AEDs: OR $2.62,95 \%$ CI 2.23 to 3.08 ), while no AED prescription was associated with a lower risk (OR $0.77,95 \%$ CI 0.68 to 0.87 ) (table 4). Other factors associated with an increased risk of mortality included experiencing status epilepticus within the past 12 months (OR 2.78, 95\% CI 1.64 to 4.71 ), depression (OR 1.67, 95\% CI 1.57 to 1.76), smoking (OR $1.45,95 \%$ CI 1.35 to 1.56 ), injury (OR $1.54,95 \%$ CI 1.43 to 1.67 ) and history of dementia (OR $1.39,95 \%$ CI 1.26 to 1.53 ) and stroke (OR 1.07, 95\% CI 1.01 to 1.14 ).

A lower risk of death was associated with seizure freedom in the previous 12 months (OR $0.52,95 \%$ CI 0.41 to 0.65 ).

We found an interaction between having an emergency department visit or emergency admission and injury (OR $0.59,95 \%$ CI 0.48 to 0.70 ).

As the cohort analysis of cause of death revealed epilepsy was a significant contributing factor of the cause of death in young PWE, we repeated the risk factor analysis for PWE aged under 35. Significant risk factors associated with risk of death included emergency department visit (OR 3.90, 95\% CI 2.44 to 6.23), number of AEDs (no AEDs: $0.42,95 \%$ CI 0.21 to $0.84,2$ AEDs: OR $1.72,95 \%$ CI 1.23 to 2.40 ; 3 AEDs OR $2.37,95 \%$ CI 1.52 to 3.67 , 4+AEDs:

Table 3 Epilepsy documented as a contributing cause of death by age group

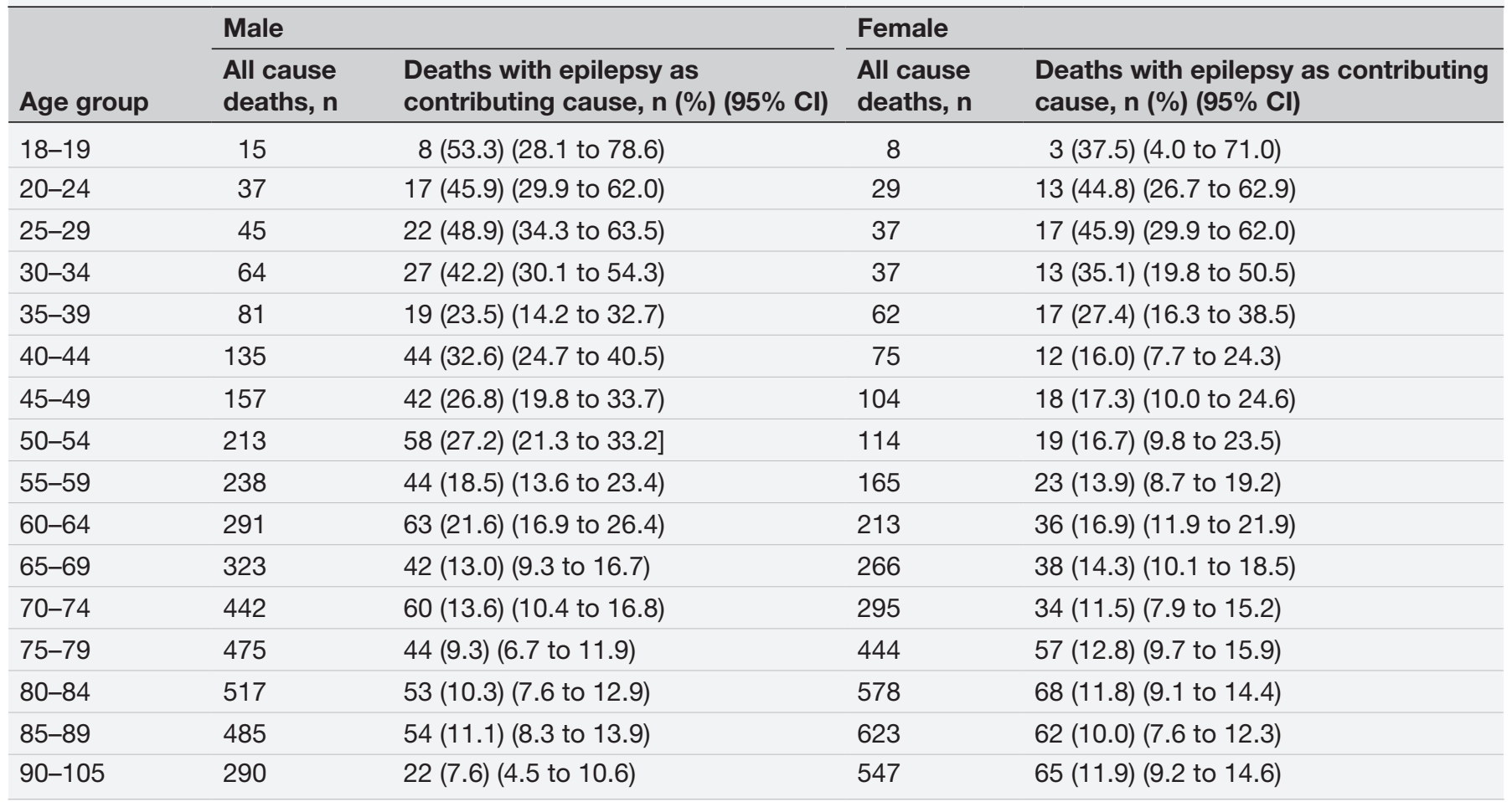


OR $3.76,95 \%$ CI 2.26 to 6.26 ), injury (OR $1.99,95 \%$ CI 1.19 to 3.31 ) and seizure freedom (OR $0.17,95 \%$ CI 0.02 to 1.44$)$.

\section{DISCUSSION}

We examined the causes of death among PWE and risk factors associated with mortality in a group of PWE derived from primary care data. The number of PWE with recorded deaths increased throughout our 9-year study period while the deaths attributed to epilepsy remained stable. In our model, we found important factors associated with a higher risk of mortality, some of which could be identified and potentially ameliorated by step-up care.

There were differences in the proportion of deaths attributed to epilepsy between younger and older PWE. Studies have found deaths of younger PWE are more often attributed to epilepsy. ${ }^{21}{ }^{22}$ Indeed, epilepsy was the third highest main cause of death in younger PWE in our study, accounting for almost $15 \%$ of deaths. This increased to $35 \%-50 \%$ when evaluating all contributing causes in age groups under 35 . As younger PWE tend to have less comorbidity than older adults, it may be simpler to attribute epilepsy as the main cause of death. New diagnoses of epilepsy in people over 65 are often secondary to cerebrovascular disease such as stroke or neoplasms in the brain. ${ }^{23}$ In our study, dementia was found to increase the risk of death, which has been found to share biological links with epilepsy. ${ }^{24}$ New-onset epilepsy in older people tends to be better controlled with AEDs. ${ }^{25}$ Thus, other comorbidity may take precedence in older PWE when documenting the cause of death, as epilepsy contributed to only about $10 \%$ of deaths and was listed as a main cause in $3 \%$.

\section{Factors associated with increased risk of death}

Our findings support evidence from previous studies. Factors associated with risk of mortality in epilepsy included: depression, ${ }^{51626}$ injuries, ${ }^{359}{ }^{5627}$ dementia and stroke, ${ }^{1328}$ age $^{13}$ and seizure freedom. ${ }^{3131516}$ Novel findings include increased risk associated with emergency department visits and/or emergency admissions, prescription of more than one AED, and status epilepticus. Status epilepticus is a known cause of death, ${ }^{13} 2229$ however, to our knowledge, it has not been included within a risk model before.

For the younger PWE group, emergency visit or emergency admissions, number of AEDs and injury were associated with higher risk of death. While, like the widersample, seizure freedom was associated with a lower risk of death.

\section{Clinical implications \\ Epilepsy management}

The need for better epilepsy management is at the core of our findings. Several risk factors are linked within this theme such as emergency department attendance, polypharmacy, injury and seizure freedom.
Visits to emergency departments or emergency admissions were associated with a threefold increased risk of death, the highest risk in our model. Visits to emergency services are associated with having injuries, ${ }^{30}$ experiencing a seizure or a change in normal seizure presentation $^{31}$ and having less confidence in self-management. ${ }^{32}$ Attendance at emergency departments for epilepsy could thus be considered a surrogate marker for poorer epilepsy control. ${ }^{33}$ The National Audit of Seizure management in Hospitals, conducted during our study period in 2011 and 2013, found $63 \%$ of PWE presenting to emergency departments for seizures had not been seen by a specialist in the previous year. ${ }^{34}$ Moreover only half of attendees were either seen by a neurologist on site or referred to one on discharge. ${ }^{34}$ These are missed opportunities to follow up with patients who may be in need of clinical review and help with self-management, to mitigate their greater risk of death.

\section{Areas for possible intervention}

Regular medication review for people on multiple AEDs may be important as increased mortality risk was associated with two or more AEDs. Prescriptions of multiple AEDs may be an effect of having more refractory and harder to control epilepsy. However, polypharmacy may also result in more side effects and different treatment schedules which could lead to more problems with medication adherence. ${ }^{35}$

Depression has been reported in about 25\% of PWE. ${ }^{36} 37$ In our study, we found $30 \%$ of cases and $20 \%$ of controls had either a diagnosis of depression or a prescription of antidepressants. Depression and other psychiatric disorders have been found to be associated with worse quality of life ${ }^{38}$ and affect self-management. ${ }^{39}$ Many PWE have said they do not feel their mental health needs are being addressed and thus depression may be underassessed in this patient group. ${ }^{40}$ As the proportion of deaths with psychiatric illness as a main cause increased twofold in our study period, psychiatric assessment and management should be provided for PWE.

Ultimately, the goal of better epilepsy management is seizure reduction or seizure freedom. Seizure freedom was associated with approximately a 50\% reduced risk of mortality in our model. Previous findings showed seizure freedom conveyed similar mortality rates for PWE as those observed in the general population. ${ }^{15}$

\section{Other factors}

We explored lifestyle factors which may be associated with increased mortality and found smoking to be associated with a higher risk. Other findings may be less amenable to change, although some intervention may be helpful. For example, experiencing status epilepticus in the previous 12 months was associated with a higher risk of death. In epilepsy, it is most often associated with low blood levels of AEDs or alcohol misuse. ${ }^{41}$ Injury to the brain (trauma, hypoxia, anoxia), tumours, infections and stroke can 
also trigger status epilepticus and thus it may not be preventable. $^{41}$

\section{Strengths and limitations}

The CPRD contains data collected from primary care which is vast and increased the generalisability of results as all participating UK practices were included. However, we relied on clinical data which has some limitations as compared with epidemiological studies. It is possible that a small number of cases might have been misclassified as having epilepsy but our case definitions of an epilepsy diagnostic code and AED prescription have been validated and used in previous studies. ${ }^{16} 1942$ Conversely, patients who presented to emergency departments or were managed only by hospital specialists might not have been included.

The quality of information in the CPRD is dependent on data entered by practice staff during consultations for clinical use, not for research purposes. Items not applicable for a patient may be left off, rather than recorded as such. In the case of diagnosis, there is no option for a GP to enter an absence of diagnosis. Missing data in routine primary care databases are not missing at random and thus statistical methods of dealing with missing data, such as multiple imputation, may not be appropriate. ${ }^{43} 44$ For this reason, we interpreted missing data as 'no' or 'no complication', however, we recognise this may be a limitation for some factors. Other limitations include not knowing the cause of injuries or hospital attendance and thus they may be unrelated to epilepsy.

We defined the exposure variables based on previous studies, if available. ${ }^{162045}$ The CPRD information has been validated for long-term conditions, such as dementia and Alzheimer's disease, and for diagnoses made by hospital consultants. ${ }^{46}$ As GPs issue prescriptions via electronic systems, the CPRD 'therapy data' has been found to be highly accurate for medication variables. ${ }^{47}$ However, we included variables which may not have been previously validated such as injury and emergency department visit or emergency admission which is a limitation of this study. We explored other factors such as severe mental illness, self-injury, patient-level IMD, alcohol use, substance use, pregnancy and learning disability. These were found statistically not significant and not included in the final overall model or the under-35 model. We also investigated interactions between variables. While we found a significant interaction between emergency admissions and injuries, we did not find one with status epilepticus. This suggests that status epilepticus might have been under recorded as a reason for emergency department visits, and perhaps entered under a more general 'epilepsy' code within GP patient notes. However, these missing episodes of status would be captured by the emergency department admission variable, which was associated with the highest risk of death in our study. We hypothesise that accurate recording of status epilepticus would have further increased its associated risk with mortality.
The time frame of our analysis corresponded to the period where epilepsy was part of the QOF, a programme whereby GPs were contracted to record specific characteristics of their patients with epilepsy. ${ }^{48}$ In particular, data on drug treatment, seizure frequency and seizure freedom were part of this programme. ${ }^{48}$ We hypothesised that this would lead to better quality data for epilepsy and strengthen the study. While the data collected may be more complete than years prior, GP practices were less successful in achieving targets for epilepsy compared with other conditions, some of which are more highly rewarded. ${ }^{48}{ }^{49}$ Older data may contain outdated diagnoses of epilepsy which may not have been reconfirmed by today's standards, and if in remission, might not have been designated with an epilepsy resolved code. This could lead to missing epilepsy data. However, the strength of the CRPD is the vast data collected from the community setting compared with hospital databases or disease-specific registers. ${ }^{19} 42$

A limitation of our cohort study is the use of linked ONS data, which is only available for consenting individuals from England and Wales. Thus, data were not available for our whole cohort, and findings are not generalisable to Scotland and Northern Ireland. Death certificate data for epilepsy has often been found to be problematic. A 2002 audit of UK data found up to $40 \%$ of deaths were attributed to the wrong cause for PWE. ${ }^{50}$ Epilepsy tends to be underestimated as a cause of death ${ }^{826}$ and dismissed for other cardiovascular or respiratory explanations. ${ }^{212651}$ Indeed, we found other diseases were listed as primary cause of death which may in fact have been epilepsy. The percentage of deaths with epilepsy as a main cause remained stable throughout our study, suggesting that practice may not have changed during this time.

\section{Research implications}

Our initial risk factor model took into account PWE of all ages. However, as the main causes of death differ between younger and older PWE, risk factors may also be different. Thus, we repeated the analysis including PWE under the age of 35 . Fewer of the variables were included in this model with the main differences being in lower ORs for having no AED prescription and being seizure free. The highest excess mortality due to epilepsy has been observed in younger people. ${ }^{15}$ This would benefit from more research aiming to identify specific risks in younger PWE, particularly as we found epilepsy contributed to close to $50 \%$ of deaths in some younger age groups. We also did not evaluate potential causes of epilepsy, such as whether stroke or tumours preceded an epilepsy diagnosis, and whether this would impact mortality. In addition, the analysis may benefit from being repeated with more recent data from the CPRD and ONS.

\section{CONCLUSION}

Several reports, including ours, have shown deaths in epilepsy continue to rise. Epilepsy is deemed a contributing cause of death particularly in young PWE, but less so in 
those over 65 . While epilepsy in older people may be better controlled with AEDs, comorbidity may mask the impact of epilepsy. We found certain factors are associated with risk of death such as emergency department attendance and admission, AED polytherapy, depression and injuries. These could be addressed with clinical intervention and more information for self-management.

\section{Author affiliations}

${ }^{1}$ Department of Basic and Clinical Neuroscience, King's College London, Institute of Psychiatry Psychology and Neuroscience, London, UK

${ }^{2}$ School of Population Health and Environmental Sciences, King's College London, London, UK

${ }^{3}$ NIHR Biomedical Research Centre at Guy's and St Thomas' NHS Foundation Trust and King's College London, London, UK

${ }^{4}$ Institute of Psychiatry, Psychology \& Neuroscience, King's College London, London, UK

Contributors GW conducted the study, statistical analysis and write-up of manuscript, and is responsible for the overall content as the guarantor. MCG contributed to the study design, supported the statistical analysis, interpretation of findings write-up. MA contributed to the study design, interpretation of findings, and write-up. MPR contributed to study design, interpretation of findings and write-up. LR contributed to the study design, interpretation, and write-up of findings.

Funding This work was partly funded by SUDEP Action (award number not applicable).

Competing interests None declared.

Patient consent for publication Not applicable.

Ethics approval This study was approved by the CPRD Independent Scientific Advisory Committee (protocol reference: 17-208R2).

Provenance and peer review Not commissioned; externally peer reviewed.

Data availability statement Data may be obtained from a third party and are not publicly available. This study uses data that is obtained from the CPRD. Requests for data must be approved via the CPRD's Research Data Governance process (formerly the Independent Scientific Advisory Committee).

Supplemental material This content has been supplied by the author(s). It has not been vetted by BMJ Publishing Group Limited (BMJ) and may not have been peer-reviewed. Any opinions or recommendations discussed are solely those of the author(s) and are not endorsed by BMJ. BMJ disclaims all liability and responsibility arising from any reliance placed on the content. Where the content includes any translated material, BMJ does not warrant the accuracy and reliability of the translations (including but not limited to local regulations, clinical guidelines, terminology, drug names and drug dosages), and is not responsible for any error and/or omissions arising from translation and adaptation or otherwise.

Open access This is an open access article distributed in accordance with the Creative Commons Attribution Non Commercial (CC BY-NC 4.0) license, which permits others to distribute, remix, adapt, build upon this work non-commercially, and license their derivative works on different terms, provided the original work is properly cited, appropriate credit is given, any changes made indicated, and the use is non-commercial. See: http://creativecommons.org/licenses/by-nc/4.0/.

\section{ORCID iDs}

Gabriella Wojewodka http://orcid.org/0000-0003-4635-4800

Martin C Gulliford http://orcid.org/0000-0003-1898-9075

Mark Ashworth http://orcid.org/0000-0001-6514-9904

\section{REFERENCES}

1 World Health Organization. Epilepsy 2019. Available: https://www. who.int/news-room/fact-sheets/detail/epilepsy [Accessed 26 Nov 2020].

2 Duncan JS, Sander JW, Sisodiya SM, et al. Adult epilepsy. Lancet 2006;367:1087-100.

3 Thurman DJ, Logroscino G, Beghi E, et al. The burden of premature mortality of epilepsy in high-income countries: a systematic review from the mortality Task force of the International League against epilepsy. Epilepsia 2017;58:17-26.

4 Neligan A, Bell GS, Shorvon SD, et al. Temporal trends in the mortality of people with epilepsy: a review. Epilepsia 2010;51:2241-6.

5 Fazel S, Wolf $\mathrm{A}$, Långström N, et al. Premature mortality in epilepsy and the role of psychiatric comorbidity: a total population study. Lancet 2013;382:1646-54.

6 Quintana M, Sánchez-López J, Mazuela G, et al. Incidence and mortality in adults with epilepsy in northern Spain. Acta Neurol Scand 2021;143:27-33.

7 Trinka E, Bauer G, Oberaigner W, et al. Cause-specific mortality among patients with epilepsy: results from a 30 -year cohort study. Epilepsia 2013;54:495-501.

8 DeGiorgio CM, Curtis A, Carapetian A, et al. Why are epilepsy mortality rates rising in the United States? A population-based multiple cause-of-death study. BMJ Open 2020;10:e035767.

9 Nilsson L, Tomson T, Farahmand BY, et al. Cause-specific mortality in epilepsy: a cohort study of more than 9,000 patients once hospitalized for epilepsy. Epilepsia 1997;38:1062-8.

10 Mbizvo GK, Bennett K, Simpson CR, et al. Epilepsy-related and other causes of mortality in people with epilepsy: a systematic review of systematic reviews. Epilepsy Res 2019;157:106192.

11 Public Health England. Deaths associated with neurological conditions in England, 2001 to 2014. London, UK: Public Health England, 2018.

12 Greenlund SF, Croft JB, Kobau R. Epilepsy by the numbers: epilepsy deaths by age, race/ethnicity, and gender in the United States significantly increased from 2005 to 2014. Epilepsy Behav 2017;69:28-30

13 Keezer MR, Bell GS, Neligan A, et al. Cause of death and predictors of mortality in a community-based cohort of people with epilepsy. Neurology 2016;86:704-12.

14 Morgan CL, Kerr MP. Epilepsy and mortality: a record linkage study in a U.K. population. Epilepsia 2002;43:1251-5.

15 Mohanraj R, Norrie J, Stephen LJ, et al. Mortality in adults with newly diagnosed and chronic epilepsy: a retrospective comparative study. Lancet Neurol 2006;5:481-7.

16 Ridsdale L, Charlton J, Ashworth M, et al. Epilepsy mortality and risk factors for death in epilepsy: a population-based study. $\mathrm{Br} J \mathrm{Gen}$ Pract 2011;61:e271-8.

17 Herrett E, Gallagher AM, Bhaskaran K, et al. Data resource profile: clinical practice research Datalink (CPRD). Int J Epidemiol 2015;44:827-36.

18 The Health and Social Care Information Centre. QOF 2004/05 background 2012.

19 Fonferko-Shadrach B, Lacey AS, White CP, et al. Validating epilepsy diagnoses in routinely collected data. Seizure 2017;52:195-8.

20 Booth HP, Prevost AT, Gulliford MC. Validity of smoking prevalence estimates from primary care electronic health records compared with national population survey data for England, 2007 to 2011. Pharmacoepidemiol Drug Saf 2013;22:1357-61.

21 Neligan A, Bell GS, Johnson AL, et al. The long-term risk of premature mortality in people with epilepsy. Brain 2011;134:388-95.

22 Lhatoo SD, Johnson AL, Goodridge DM, et al. Mortality in epilepsy in the first 11 to 14 years after diagnosis: multivariate analysis of a long-term, prospective, population-based cohort. Ann Neurol 2001;49:336-44.

23 Sen A, Jette N, Husain M, et al. Epilepsy in older people. Lancet 2020;395:735-48.

24 Sen A, Capelli V, Husain M. Cognition and dementia in older patients with epilepsy. Brain 2018;141:1592-608.

25 Johnston A, Smith P. Epilepsy in the older patient. Rev Clin Gerontol 2007:17:109-18.

26 Devinsky O, Hesdorffer DC, Thurman DJ, et al. Sudden unexpected death in epilepsy: epidemiology, mechanisms, and prevention. Lancet Neurol 2016;15:1075-88.

27 Rafnsson V, Olafsson E, Hauser WA, et al. Cause-specific mortality in adults with unprovoked seizures. A population-based incidence cohort study. Neuroepidemiology 2001;20:232-6.

28 Blank LJ, Acton EK, Willis AW. Predictors of mortality in older adults with epilepsy: implications for learning health systems. Neurology 2021;96:e93-101.

29 Lip GY, Brodie MJ. Sudden death in epilepsy: an avoidable outcome? J R Soc Med 1992;85:609-11.

30 Faught E, Duh MS, Weiner JR, et al. Nonadherence to antiepileptic drugs and increased mortality: findings from the RANSOM study. Neurology 2008;71:1572-8.

31 McKinlay A, Morgan M, Noble A, et al. Patient views on use of emergency and alternative care services for adult epilepsy: a qualitative study. Seizure 2020;80:56-62. 
32 Noble AJ, Morgan M, Virdi C, et al. A nurse-led self-management intervention for people who attend emergency departments with epilepsy: the patients' view. J Neurol 2013;260:1022-30.

33 Shohet C, Yelloly J, Bingham P, et al. The association between the quality of epilepsy management in primary care, general practice population deprivation status and epilepsy-related emergency hospitalisations. Seizure 2007;16:351-5.

34 Dixon PA, Kirkham JJ, Marson AG, et al. National audit of seizure management in hospitals (NASH): results of the National audit of adult epilepsy in the UK. BMJ Open 2015;5:e007325.

35 Wojewodka G, McKinlay A, Ridsdale L. Best care for older people with epilepsy: a scoping review. Seizure 2021;85:70-89.

36 Tellez-Zenteno JF, Patten SB, Jetté N, et al. Psychiatric comorbidity in epilepsy: a population-based analysis. Epilepsia 2007;48:2336-44.

37 Scott AJ, Sharpe L, Hunt C, et al. Anxiety and depressive disorders in people with epilepsy: a meta-analysis. Epilepsia 2017;58:973-82.

38 Ridsdale L, Wojewodka G, Robinson E, et al. Characteristics associated with quality of life among people with drug-resistant epilepsy. J Neurol 2017;264:1174-84.

39 Dilorio C, Shafer PO, Letz R, et al. Behavioral, social, and affective factors associated with self-efficacy for self-management among people with epilepsy. Epilepsy Behav 2006;9:158-63.

40 Neurological Alliance. Parity of Esteem. UK, 2017.

41 Trinka E, Höfler J, Zerbs A. Causes of status epilepticus. Epilepsia 2012;53(Suppl 4):127-38.

42 Tan M, Wilson I, Braganza V, et al. Development and validation of an epidemiologic case definition of epilepsy for use with routinely collected Australian health data. Epilepsy Behav 2015;51:65-72.
43 Marston L, Carpenter JR, Walters KR, et al. Issues in multiple imputation of missing data for large general practice clinical databases. Pharmacoepidemiol Drug Saf 2010;19:618-26.

44 Steele AJ, Denaxas SC, Shah AD, et al. Machine learning models in electronic health records can outperform conventional surviva models for predicting patient mortality in coronary artery disease. PLoS One 2018;13:e0202344.

45 Dunn N, Holmes C, Mullee M. Does lithium therapy protect against the onset of dementia? Alzheimer Dis Assoc Disord 2005;19:20-2.

46 Khan NF, Harrison SE, Rose PW. Validity of diagnostic coding within the general practice research database: a systematic review. $\mathrm{Br} J$ Gen Pract 2010;60:e128-36.

47 Jick H, Jick SS, Derby LE. Validation of information recorded on general practitioner based computerised data resource in the United Kingdom. BMJ 1991;302:766-8.

48 Health and Social Care Information Centre. National quality and outcomes framework statistics for England 2004/05: health and social care information centre, 2005.

49 Prescribing and Primary Care Services HaSCIC. Quality and outcomes framework - prevalence, achievements and exceptions report. England 2013-2014, 2014.

50 Hanna NJ, Black M, Sander JWS. The National sentinel clinical audit of epilepsy-related death: epilepsy - death in the shadows, 2002.

51 Kim AS, Moffatt E, Ursell PC, et al. Sudden neurologic death masquerading as out-of-hospital sudden cardiac death. Neurology 2016;87:1669-73. 